\title{
RESULTADOS DO ENADE/2009 DOS CURSOS DE ESTATÍSTICAS EM DISCUSSÃO
}

\author{
Regina Serrão Lanzillotti*; Haydée Serrão Lanzillotti**
}

Recebido: 30 maio $2012 \quad$ Aprovado: 08 nov. 2012

\begin{abstract}
*Universidade do Estado do Rio de Janeiro. Rio de Janeiro, RJ, Brasil. Contato: reginalanzillotti@terra.com.br **Universidade do Estado do Rio de Janeiro. Rio de Janeiro, RJ, Brasil. Contato: haydeelan@gmail.com

Resumo: Objetiva-se confrontar os resultados do ENADE-2009/Estatística entre as IES. A avaliação para a Formação Geral (FG) abordou estudos de caso, simulações, interpretação de textos, análise gráfica e tabular, enquanto a Formação Específica (FE), estudos de casos. As notas foram padronizadas pelo desvio padrão com ajuste para variar no intervalo de zero a cinco, considerando o afastamento padronizado ao módulo do menor, dividido pela soma do maior com o módulo do menor, o quociente foi multiplicado por cinco, os inferiores a $-3,0$ e superior a 3,0, não foram utilizados e recebem zero e cinco, respectivamente. Os padronizados foram convertidos em percentis da Curva Normal Padrão e permitiram traçar gráficos para aferir padrão de classificação tanto para concluintes quanto para ingressantes.
\end{abstract}

Palavras-chave: ENDADE/2009. Desempenho acadêmico. Cursos de estatística.

\section{RESULTS OF ENADE/2009 STATISTICS PROGRAMS DISCUSSED}

Abstract: This study aims at comparing the results of ENADE-2009/Statistics programs of different higher education institutions. The evaluation of the General Education (GF) part of the examination involved case studies, simulations, text interpretation, tabular and graphical analysis, while the Specific Component (EF) dealt with case studies. The scores were standardized by standard deviation adjusted to vary in the range of zero to five, considering the standard lag to the lower module, divided by the sum of the largest with smallest module, the quotient was multiplied by five. Standard less than -3.0 and greater than 3.0 were not used and receive zero and five, respectively. The standardized values were converted to percentiles of the Standard Normal Curve and allowed to draw graphs to both, freshmen and senior students.

Key words: ENADE/2009. Academic performance. Statistics programs. 


\section{INTRODUÇÃO}

A Portaria Normativa No 1 , de 29 de Janeiro de 2009 do MEC (BRASIL; MEC, 2011) determinou as áreas e os cursos superiores de tecnologia integrantes do Exame Nacional de Desempenho dos Estudantes (ENADE) no ano de 2009. O Ministro de Estado da Educação, no uso de suas atribuições e tendo em vista o disposto na Lei $\mathrm{n}^{\mathrm{o}} 10.861$, de 14 de abril de 2004, que instituiu o Sistema Nacional de Avaliação da Educação Superior (SINAES) e na Portaria no 2.051, de 9 de julho de 2004, que regulamentou os procedimentos de avaliação do SINAES, resolveu que seriam avaliados pelo ENADE/2009, dentre outras áreas, a área de Estatística. $\mathrm{O}$ exame foi realizado no dia 08 de novembro de 2009 pelos estudantes do final do primeiro e do último ano, independentemente da organização curricular adotada pela Instituição Ensino Superior - IES.

Foram considerados estudantes do final do primeiro ano do curso aqueles que, até o dia $1^{\circ}$ de agosto de 2009 , tivessem concluído entre $7 \%$ (sete por cento) e $22 \%$ (vinte e dois por cento), inclusive, da carga horária mínima do currículo do curso das IES. Também foram incluídos, os estudantes do último ano do curso, aqueles que, até o dia $1^{\circ}$ de agosto de 2009, tivessem concluído pelo menos $80 \%$ (oitenta por cento) da carga horária mínima do currículo do curso da IES ou aquele estudante que tivesse condições acadêmicas de conclusão do curso no ano letivo de 2009. Ficaram dispensados do ENADE 2009 os estudantes com colação de grau realizada até o dia 31 de agosto de 2009 e aqueles que estivessem oficialmente matriculados e cursando atividades curriculares fora do Brasil, na data de realização deste exame em instituição conveniada com a IES de origem do estudante e também os estudantes inscritos que não foram selecionados pelo Instituto Nacional de Estudos e Pesquisas Educacionais Anísio Teixeira (INEP).

O INEP enviou as instruções e os instrumentos necessários ao cadastramento eletrônico dos estudantes habilitados aos dirigentes das IES que oferecessem cursos de Estatística, conforme cadastro do Portal SiedSup - Informação sobre IES com prazo até o dia 29 de maio de 2009. Os dirigentes das IES foram responsáveis pela inscrição de todos os estudantes habilitados ao ENADE 2009 e deveriam devolver os instrumentos mencionados devidamente preenchidos com os dados cadastrais dos estudantes no período de 29 de junho a 31 de agosto de 2009.

Conforme disposto no art. $5^{\circ}, \S 7^{\circ}$ da Lei no 10.861 , de 14 de abril de 2004 (BRASIL; MEC, 2004a), a não-inscrição de alunos habilitados para participarem no ENADE nos prazos estipulados poderá ensejar a suspensão temporária da abertura de processo seletivo para as áreas de Estatística na IES. Era de 
responsabilidade dos dirigentes das IES divulgar amplamente, junto ao seu corpo discente, a lista dos estudantes cadastrados para o ENADE 2009 e os locais onde seriam aplicadas as provas.

Coube ao Presidente do INEP designar os professores que integrariam a Comissão Assessora de Avaliação da Formação Geral e as Comissões Assessoras de Área, consideradas as áreas e os cursos superiores de tecnologia para definirem as competências, conhecimentos, saberes e habilidades a serem avaliadas e todas as especificações necessárias à elaboração da prova a ser aplicada no ENADE 2009, até o dia 26 de junho de 2009.

Tendo em vista a Lei 10.861 , de 14 de abril de 2004, a Portaria Normativa $\mathrm{n}^{\mathrm{o}} 1$, de 29 de janeiro de 2009, a Lei ${ }^{\circ} 11.507$, de 20 de julho de 2007 e nos termos do art. $9^{\circ}$, VI, VIII e IX, da Lei $n^{\circ} 9.394$, de 20 de dezembro de 1996, o presidente do INEP, na Portaria INEP n 83, de 4 de maio de 2009 designou professores para compor as Comissões Assessoras de Avaliação das Áreas de Formação Geral e dentre outras, a de Estatística. As atividades das Comissões foram encerradas cento e oitenta dias após a data de divulgação oficial dos resultados do ENADE 2009. Estas Comissões estavam vinculadas à Diretoria de Avaliação da Educação Superior (DAES) do INEP e tinham como atribuições:

a) propor diretrizes, objetivos e outras especificações necessárias à elaboração dos instrumentos de avaliação a serem aplicados no ENADE dos Cursos de Graduação nas áreas avaliadas;

b) formular propostas para o aprimoramento do ENADE, em colaboração com a DAES.

O Presidente do INEP no uso de suas atribuições, tendo em vista a Lei $\mathrm{n}^{\circ}$ 10.861, de 14 de abril de 2004; a Portaria Ministerial $n^{\circ} 2.051$, de 9 de julho de 2004 (BRASIL; MEC, 2004a), a Portaria Normativa $n^{0} 1$, de 29 de janeiro de 2009, e considerando as definições estabelecidas pelas Comissões Assessoras de Avaliação da Área de Estatística e da Formação Geral do ENADE, nomeadas pela Portaria INEP $n^{\circ}$ 83, de 04 de maio de 2009, resolveu que o ENADE, parte integrante do SINAES objetiva avaliar o desempenho dos estudantes em relação aos conteúdos programáticos previstos nas diretrizes curriculares, às habilidades e competências para a atualização permanente e aos conhecimentos sobre a realidade brasileira, mundial e sobre outras áreas do conhecimento.

A resolução $\mathrm{n}^{\circ}$ 8, de 28 de novembro de 2008 (BRASIL; MEC, 2008) que institui as Diretrizes Curriculares Nacionais do curso de Estatística, de graduação plena, em nível superior, e dá outras providências indica que o projeto 
pedagógico do curso de graduação em Estatística, além da clara concepção do curso, com suas peculiaridades, sua matriz curricular e sua operacionalização, deverá incluir, pelo menos, os seguintes elementos:

I - objetivos gerais do curso, contextualizados em relação às suas inserções institucionais, política, geográfica e social; II - condições objetivas de oferta e a vocação do curso; III - formas de implementação da interdisciplinaridade; IV - formas de integração entre teoria e prática; V - formas de avaliação do ensino e da aprendizagem; VI - formas de integração entre graduação e pósgraduação, quando houver; VII - incentivo à investigação, como necessário prolongamento da atividade de ensino e como instrumento para a iniciação científica; VIII - regulamentação das atividades relacionadas com o trabalho de curso (quando houver) de acordo com as normas da instituição de ensino, sob diferentes modalidades; IX - concepção e composição das atividades de estágio curricular supervisionado (quando houver) contendo suas diferentes formas e condições de realização, observado o respectivo regulamento; X concepção e composição das atividades complementares desenvolvendo a sua capacidade para: I - abordar com proficiência os problemas usuais de sua área de atuação: coleta, organização e síntese de dados, ajuste de modelos, com base em conhecimentos sólidos e atualizados; II - investigar e programar soluções para problemas novos e interpretar criticamente novos conhecimentos; III assumir postura ética diante dos fatos.

Acresce a experiência que viabiliza a flexibilização curricular e indissociabilidade entre Ensino, Pesquisa e Extensão nas Universidades Públicas Brasileiras que objetiva formar profissionais pró-ativos com orientação pedagógica norteada às tecnologias sociais e à inclusão incentivando à capacidade analítica, direcionando a oferta de mão de obra especializada a iniciativa pública e privada em interface com a pesquisa aplicada e/ou desenvolvimento tecnológico. Criando-se uma relação dialógica entre pesquisadores e sociedade. A aferição da IES pelo ENADE propicia verificar se a atual formação do estatístico atenderá a demanda de um mercado de trabalho que pontua a capacitação e, quando necessário, a adaptação as situações inesperadas advindas às atividades laborais.

As IES devem conduzir tanto os ingressantes quantos os concluintes a enfrentar desafios, promover o inter-relacionamento pessoal, desenvolver a comunicação oral e escrita, estar aberto ao aprendizado de novas técnicas e métodos inferenciais e adaptar-se a equipes multidisciplinares. O estatístico atua em diferentes áreas do conhecimento e como foi dito na matéria publicada na mídia, Estatística, a profissão do futuro, o estatístico é o profissional que 
deve saber projetar e interpretar os dados disponíveis, transformando-os em informações relevantes.

A prova do ENADE 2009 teve duração total de 4 (quatro) horas, constando de uma avaliação do componente de Formação Geral comum aos cursos de todas as áreas e um Componente Específico da área de Estatística. O componente de Formação Geral do ENADE foi construído com 10 (dez) questões, sendo 2 (duas) discursivas e 8 (oito) de múltipla escolha, que abordaram situaçõesproblema, estudos de caso, simulações e interpretação de textos, imagens, gráficos e tabelas. Em seu Componente Específico da área de Estatística, 30 (trinta) questões, sendo 3 (três) discursivas e 27 (vinte e sete) de múltipla escolha, envolvendo situações-problema e estudos de casos. As questões discursivas avaliaram aspectos como clareza, coerência, coesão, estratégias argumentativas, utilização de vocabulário adequado e correção gramatical do texto. A Comissão Assessora de Avaliação da área de Estatística e a Comissão Assessora de Avaliação da Formação Geral subsidiarão a banca responsável pela elaboração do instrumento avaliador com informações adicionais sobre a prova do ENADE 2009.

Na componente de Formação Geral foi considerada a formação de um profissional ético, competente e comprometido com a sociedade em que vive. Além do domínio de conhecimentos e de níveis diversificados de habilidades e competências para perfis profissionais específicos, esperava-se que os graduandos das IES evidenciassem a compreensão de temas que possam transcender ao seu ambiente próprio de formação e fossem importantes para a realidade contemporânea. Essa compreensão vinculava-se as perspectivas críticas, integradoras e à construção de sínteses contextualizadas. As questões do componente de Formação Geral versariam sobre alguns dentre os seguintes temas: Ecologia; Biodiversidade; Arte, Cultura e Filosofia; Mapas Geopolíticos e Socioeconômicos; Globalização; Políticas Públicas: Educação, Habitação, Saneamento, Saúde, Segurança, Defesa, Desenvolvimento sustentável; Redes sociais e responsabilidade: Setor público e setor privado, Terceiro setor; Relações interpessoais: respeitar, cuidar, considerar, conviver; Sociodiversidade: multiculturalismo, tolerância, inclusão; Exclusão e minorias; Relações de gênero; Vida urbana e rural; Democracia e cidadania; Violência; Terrorismo; Avanços tecnológicos; Inclusão/exclusão digital; Relações de trabalho; Tecnociência; Propriedade intelectual; Diferentes mídias e tratamento da informação.

No componente de Formação Geral, foram verificadas as capacidades de ler e interpretar textos; analisar e criticar informações; extrair conclusões por indução e/ou dedução; estabelecer relações, comparações e contrastes em 
diferentes situações; detectar contradições; fazer escolhas valorativas avaliando conseqüências; questionar a realidade; argumentar coerentemente. Neste mesmo componente, os estudantes deverão mostrar competência para: propor ações de intervenção e soluções para situações-problema; elaborar perspectivas integradoras e sínteses; administrar conflitos.

No Componente Específico da área de Estatística, objetivava-se aferir aptidão para dar continuidade aos estudos em cursos de pós-graduação e resolver problemas estatísticos identificados nas diversas áreas do conhecimento. Tomou-se como referência o seguinte perfil do profissional: ética na atuação profissional; responsabilidade social e ambiental; capacidade de expressão e comunicação; capacidade de interagir em equipes multidisciplinares; raciocínio lógico/analítico/sistêmico; familiaridade com uso de recursos computacionais; capacidade crítica, investigativa e criativa; identificar, modelar e solucionar problemas estatísticos; realizar pesquisas bibliográficas e em bases de dados. Avaliaria se o estudante desenvolveu, no processo de formação, as seguintes habilidades e competências: saber planejar e conhecer formas de coleta de dados estatísticos; saber criticar, apurar e apresentar os resultados estatísticos; saber produzir relatórios e sínteses numéricas e gráficas; conhecer distribuições de variáveis aleatórias; saber identificar e apresentar soluções de análise, contemplando restrições e especificidades dos modelos estatísticos; saber utilizar recursos computacionais para solucionar problemas estatísticos. Tomou como referencial os seguintes conteúdos que poderiam exigir conhecimentos de cálculo diferencial e integral, álgebra linear, geometria analítica e recursos computacionais: Probabilidade: variáveis aleatórias: uni e multidimensionais, discretas e contínuas, momentos e separatrizes (quantis); teorema central do limite e lei dos grandes números; transformações de variáveis aleatórias; simulação de variáveis aleatórias, enquanto Estatística: estatística descritiva; estimação: pontual, intervalar, propriedades, teste de hipótese: paramétrico e não paramétrico; amostragem; modelos lineares: análise de variância, regressão linear.

O objetivo do trabalho foi confrontar os resultados dos conceitos do ENADE/2009 - Estatística entre as IES participantes.

\section{MÉTODOS E TÉCNICAS}

O Conceito Preliminar de Curso (CPC) estipulado pelo ENADE é calculado para cada curso da IES por município de uma área de avaliação com valores inteiros entre 1 e 5 inclusive para as notas finais referentes a intervalos de 0,0 a $0,9,1,0$ a 1,9, 2,0 a 2,9, 3,0 a 3,9 e 4,0 a 5,0, respectivamente. A Nota Final do 
curso corresponde à média ponderada das notas padronizadas dos concluintes no Componente Específico e na Formação Geral com pesos de 75\% e 25\%, respectivamente, em consonância com as questões da prova, 30 e 10, respectivamente. Oito medidas de qualidade compõem o CPC do curso:

a) Nota de Professores Doutores, corresponde à proporção de professores vinculados ao curso cuja titulação seja igual ou maior a esta titulação, padronizada e transformada em valor entre 0 e 5 .

b) Nota de Professores Mestres, corresponde à proporção de professores vinculados ao curso cuja titulação seja maior ou igual a esta titulação, sendo padronizada e transformada em valor entre 0 e 5 .

c) Nota de Regime de um curso corresponde à proporção de professores vinculados cujo regime de dedicação seja integral ou parcial, sendo padronizada e transformada em valor entre 0 e 5.

d) Nota de Infra-Estrutura corresponde à proporção de alunos do curso que avaliaram positivamente a questão, "Aulas práticas: os equipamentos disponíveis são suficientes para todos os alunos?", tendo cinco alternativas de resposta, consideradas positivas apenas (A) ou (B) entre: $(A)=\operatorname{Sim}$, em todas elas; $(\mathrm{B})=$ Sim, na maior parte delas; $(\mathrm{C})=$ Sim, mas apenas na metade delas; (D) = Sim, mas em menos da metade delas; $(E)$ = Não, em nenhuma Essa medida foi padronizada e transformada em valor entre 0 e 5 .

e) Nota de Organização Didático-Pedagógica corresponde à proporção de alunos que avaliaram positivamente a questão "Os planos de ensino contêm todos os seguintes aspectos: objetivos; procedimentos de ensino e avaliação; conteúdos e bibliografia da disciplina", com cinco alternativas de resposta, sendo considerado positivo a alternativa $(A)$ entre $(A)=\operatorname{Sim}$, todos contém; $(\mathrm{B})=\mathrm{Sim}$, a maior parte contém; $(\mathrm{C})=\mathrm{Sim}$, mas apenas cerca da metade contém; (D) = Sim, mas apenas menos da metade contém. $(E)=$ Não, nenhum contém. Essa medida foi padronizada e transformada, em valor entre 0 e 5 .

f) Nota dos Concluintes no ENADE corresponde à nota final que dá origem ao Conceito ENADE. Portanto, para cada curso é composta por: $75 \%$ da nota dos alunos concluintes no componente específico do ENADE e 25\% da nota dos mesmos alunos no componente de Formação Geral, as notas padronizadas e transformadas na escala de 0 a 5 .

g) Nota dos Ingressantes no ENADE calculada conforme a mesma metodologia que a Nota dos Concluintes 
h) Indicador de Diferença entre os Desempenhos Observado e Esperado (IDD) tem o propósito de trazer às instituições informações comparativas dos desempenhos de seus estudantes concluintes em relação aos resultados médios obtidos pelos concluintes das demais instituições que possuem estudantes ingressantes de perfil semelhante ao seu. É resultante da diferença entre o desempenho médio obtido no ENADE pelos alunos concluintes de um curso e o desempenho médio que era esperado para esses mesmos alunos, dadas as informações existentes sobre o perfil dos ingressantes desse curso. Os fatores que determinam o desempenho médio dos estudantes concluintes de um determinado curso podem ser separados, por hipótese, em três parcelas: a primeira determinada pelas características de ingresso destes alunos concluintes em termos de aprendizagem; outra determinada pela qualidade da formação oferecida pelo curso; e, por fim, um termo de erro que capta os outros elementos que afetam o desempenho do aluno.

\section{RESULTADOS}

As IES que participaram desta atividade de avaliação estão arroladas na Tabela1 com a freqüência relativa dos inscritos, 710 ingressantes e 443 concluintes, respectivamente. As instituições que mais prestigiaram este exame foram Universidade Federal do Paraná (ingressantes e concluintes), Escola Nacional de Ciências Estatísticas (ingressantes) e Universidade Federal de Sergipe (ingressantes), Universidade Estadual da Paraíba (concluintes) e Universidade Federal de São Carlos (concluintes). Nestas instituições, acredita-se que os educadores da Universidade Federal do Paraná persuadiram seus alunos para a importância desta avaliação no sentido da qualificação da opção pelo processo pedagógico vigente.

Bussab e Morettin (2002) propõe o uso de valores padronizados e respectivos percentis da Curva Normal Padrão, aqui utilizados para as avaliações, tanto para ingressantes quanto para os concluintes, Tabela 2. Os valores médios e respectivos desvios padrões da avaliação das Entidades de Ensino Superior estão no cabeçalho da tabela, sendo que os valores médios dos ingressantes em Formação Geral foi um pouco maior do que dos concluintes (44,03 contra 43,04), pois parece que os conteúdos que contribuem para a atualização dos fatos relativos à formação cultural estão sendo negligenciados ao longo do curso. No caso do Componente Específico, a média relativa aos ingressantes foi menor do que a dos concluintes $(20,68$ contra 30,78$)$, resultado esperado, pois os conceitos inerentes ao conteúdo programático não seriam tão abrangentes 
para os iniciantes. Cabe lembrar que para a Formação Geral a variabilidade em torno da média ficou entre $25 \%$ e $27 \%$, enquanto para o Componente Específico, entre $22 \%$ e $30 \%$, o que indica uma heterogeneidade maior para a aferição dos conteúdos inerentes a formação técnica.

Tabela 1 - Distribuição percentual dos alunos dos cursos de Estatística ENADE/2009

\begin{tabular}{|c|c|c|c|}
\hline \multirow{3}{*}{ Entidades de Ensino Superior } & \multirow{3}{*}{ Sigla } & \multicolumn{2}{|c|}{ Participantes } \\
\hline & & \multicolumn{2}{|c|}{ \% } \\
\hline & & $\begin{array}{c}\text { Ingressantes } \\
(n=710)\end{array}$ & $\begin{array}{c}\text { Concluintes } \\
(n=443)\end{array}$ \\
\hline \multicolumn{4}{|l|}{ Pública } \\
\hline Universidade Federal de Minas Gerais & UFMG & 3,38 & 4,97 \\
\hline Universidade Federal do Rio de Janeiro & UFRJ & 0,56 & 2,26 \\
\hline Universidade de Brasília & UNB & 5,07 & 6,55 \\
\hline Universidade Federal do Espírito Santo & UFES & 2,39 & 1,81 \\
\hline Universidade Federal do Ceará & UFC & 6,20 & 3,39 \\
\hline $\begin{array}{l}\text { Universidade Federal do Rio Grande } \\
\text { do Sul }\end{array}$ & UFRGS & 3,80 & 2,48 \\
\hline $\begin{array}{l}\text { Universidade Estadual Paulista Júlio } \\
\text { de Mesquita Filho }\end{array}$ & UNESP & 3,52 & 4,74 \\
\hline Universidade Estadual de Maringá & UEM & 2,11 & 4,06 \\
\hline Universidade Federal de São Carlos & UFSCAR & 4,51 & 7,00 \\
\hline Universidade Federal do Amazonas & UFAM & 4,23 & 3,16 \\
\hline $\begin{array}{l}\text { Escola Nacional de Ciências } \\
\text { Estatísticas }\end{array}$ & ENCE & 8,03 & 4,97 \\
\hline Universidade federal do Paraná & UFPR & 11,13 & 10,84 \\
\hline $\begin{array}{l}\text { Universidade federal do Rio Grande } \\
\text { do Norte }\end{array}$ & UFRN & 4,51 & 1,58 \\
\hline Universidade federal do Pará & UFPA & 3,66 & 6,09 \\
\hline $\begin{array}{l}\text { Universidade do estado do Rio de } \\
\text { Janeiro }\end{array}$ & UERJ & 5,07 & 11,96 \\
\hline Universidade Federal da Bahia & UFBA & 3,80 & 2,26 \\
\hline Universidade Federal de Sergipe & UFS & 7,04 & 2,26 \\
\hline Universidade Estadual da Paraíba & UEPB & 5,92 & 9,71 \\
\hline Universidade Federal de Juiz De Fora & UFJF & 1,13 & - \\
\hline Universidade Federal de Ouro Preto & UFOP & 2,54 & - \\
\hline Universidade Federal do Piauí & UFPI & 1,69 & - \\
\hline Universidade Federal Fluminense & UFF & 3,38 & - \\
\hline Universidade Federal de Goiás & UFG & 4,79 & - \\
\hline Centro Universitário Capital & UNICAPITAL & 1,55 & 3,39 \\
\hline Escola Superior de Estatística da Bahia & ESEB & - & 6,55 \\
\hline $\begin{array}{ll} & \text { Total } \\
\end{array}$ & & 100,00 & 100,00 \\
\hline
\end{tabular}


Tabela 2 - Valores padronizados e percentis da Curva Normal ENADE/2009- Curso de Estatística

\begin{tabular}{|c|c|c|c|c|c|c|c|c|}
\hline \multirow[b]{2}{*}{ Sigla } & \multicolumn{4}{|c|}{ Ingressantes } & \multicolumn{4}{|c|}{ Concluintes } \\
\hline & $\begin{array}{c}\text { Formação } \\
\text { Geral } \\
\mu=44,03 \\
\sigma=11,99\end{array}$ & $\%$ & $\begin{array}{c}\text { Componente } \\
\text { Específico } \\
\mu=20,68 \\
\sigma=4,51\end{array}$ & $\%$ & $\begin{array}{c}\text { Formação } \\
\text { Geral } \\
\mu=43,04 \\
\sigma=10,88\end{array}$ & $\%$ & $\begin{array}{c}\text { Componente } \\
\text { Específico } \\
\mu=30,78 \\
\sigma=9,27\end{array}$ & $\%$ \\
\hline UFMG & 0,21 & 58 & 1,09 & 86 & 1,21 & 89 & 2,54 & 99 \\
\hline UFRJ & 2,17 & 98 & 2,82 & 100 & 1,89 & 97 & 1,66 & 95 \\
\hline UNB & 0,28 & 61 & $-0,64$ & 26 & 1,10 & 87 & 1,24 & 89 \\
\hline UFES & 0,24 & 60 & $-0,15$ & 44 & 0,00 & 50 & 0,79 & 78 \\
\hline UFC & 0,18 & 57 & $-0,39$ & 35 & 1,02 & 85 & 0,42 & 66 \\
\hline UFRGS & 1,55 & 94 & 0,40 & 65 & 0,03 & 51 & 0,58 & 72 \\
\hline UNESP & 0,19 & 57 & 1,07 & 86 & 1,13 & 87 & $-0,12$ & 45 \\
\hline UEM & $-0,12$ & 45 & 0,81 & 79 & $-0,18$ & 43 & 0,33 & 63 \\
\hline UFSCAR & 1,29 & 90 & 0,59 & 72 & 0,55 & 71 & $-0,01$ & 50 \\
\hline UFAM & $-1,23$ & 11 & $-0,67$ & 25 & $-1,04$ & 15 & 0,43 & 66 \\
\hline ENCE & 0,11 & 54 & 0,52 & 70 & 0,10 & 54 & $-0,05$ & 48 \\
\hline UFPR & 0,24 & 59 & 0,40 & 66 & 0,84 & 80 & $-0,36$ & 36 \\
\hline UFRN & $-0,89$ & 19 & $-0,46$ & 32 & $-1,15$ & 13 & $-0,56$ & 29 \\
\hline UFPA & $-0,87$ & 19 & $-1,22$ & 11 & 0,07 & 53 & $-1,08$ & 14 \\
\hline UERJ & $-0,96$ & 17 & $-0,12$ & 45 & $-0,75$ & 23 & $-0,80$ & 21 \\
\hline UFBA & $-0,61$ & 27 & $-2,38$ & 1 & $-1,80$ & 4 & $-0,65$ & 26 \\
\hline UFS & $-1,26$ & 10 & $-1,19$ & 12 & $-1,21$ & 11 & $-0,92$ & 18 \\
\hline UEPB & $-1,55$ & 6 & $-0,71$ & 24 & $-1,34$ & 9 & $-1,43$ & 8 \\
\hline UFJF & 2,01 & 98 & 0,74 & 77 & - & - & - & - \\
\hline UFOP & 0,41 & 66 & $-0,33$ & 37 & - & - & - & - \\
\hline UFPI & $-0,82$ & 21 & 0,23 & 59 & - & - & - & - \\
\hline UFF & 0,22 & 59 & $-0,28$ & 39 & - & - & - & - \\
\hline UFG & $-0,80$ & 21 & $-0,15$ & 44 & - & - & - & - \\
\hline UNICAPITAL & 0,81 & 79 & $-0,41$ & 34 & 0,40 & 66 & $-0,65$ & 26 \\
\hline ESEB & - & - & & & $-0,87$ & 19 & $-1,36$ & 9 \\
\hline
\end{tabular}


Os percentis da Curva Normal Padrão, separatrizes, permite a comparação sob a forma escalar de um segmento de dimensão 100 (cem), os valores menores, correspondem a uma situação mais desfavorável de avaliação, enquanto os maiores, uma situação de qualificação superior. Estabelecendo um corte na décima parte superior deste segmento (percentil 90), os ingressantes que mais se destacaram em relação ao desempenho na aferição da Formação Geral foram os da UFRJ, UFJF, UFRGS e UFSCAR enquanto para os concluintes, somente a UFRJ. No Componente Específico, para este mesmo corte, a UFRJ (ingressantes e concluintes) e a UFMG (concluintes). Desta apreciação, cabe a UFRJ e a UFMG o padrão de excelência na formação dos estatísticos, embora sejam as IES que acolheram menos inscritos nesta atividade avaliativa em relação às demais.

Os percentis da Curva Normal subsidiaram a criação de gráficos de dispersão para os alunos ingressantes e concluintes, Figura 1 e Figura 2, respectivamente. No caso dos ingressantes, a UFRJ destaca-se dentre as que apresentaram melhores resultados tanto para a Formação Geral quanto para Componente Específico, seguida da UFSCAR, UFRGS e UFJF, sendo que estas duas últimas apresentaram melhores resultados na Formação Geral do que na Componente Específica. As IES que estão no quadrante inferior à esquerda, UEPB, UFAM, UFS, UFPB e UFBA, apresentaram resultados preocupantes para os alunos de graduação que se encontram no início do curso, sendo esperado que se proceda a uma reavaliação em relação aos recursos didático-pedagógicos utilizados pelo corpo docente e futuramente, provavelmente receberão uma visita dos avaliadores de cursos do MEC.

Construindo este mesmo gráfico para os concluintes, visualiza-se mostra que os cursos de maior destaque estão próximo ao vértice superior direito (UFMG, UFRJ e UNB) e são aqueles que têm formado estatísticos bem preparados para o mercado de trabalho. As IES que se posicionaram no extremo oposto, são aquelas em que os coordenadores de curso e os gestores educacionais destas instituições devem repensar uma forma de atender as Diretrizes Curriculares do Curso de Estatística e rever métodos didáticos pedagógicos. 
Figura 1 - Percentis da Curva Normal Padrão para IES, ENADE/Avaliação dos ingressantes

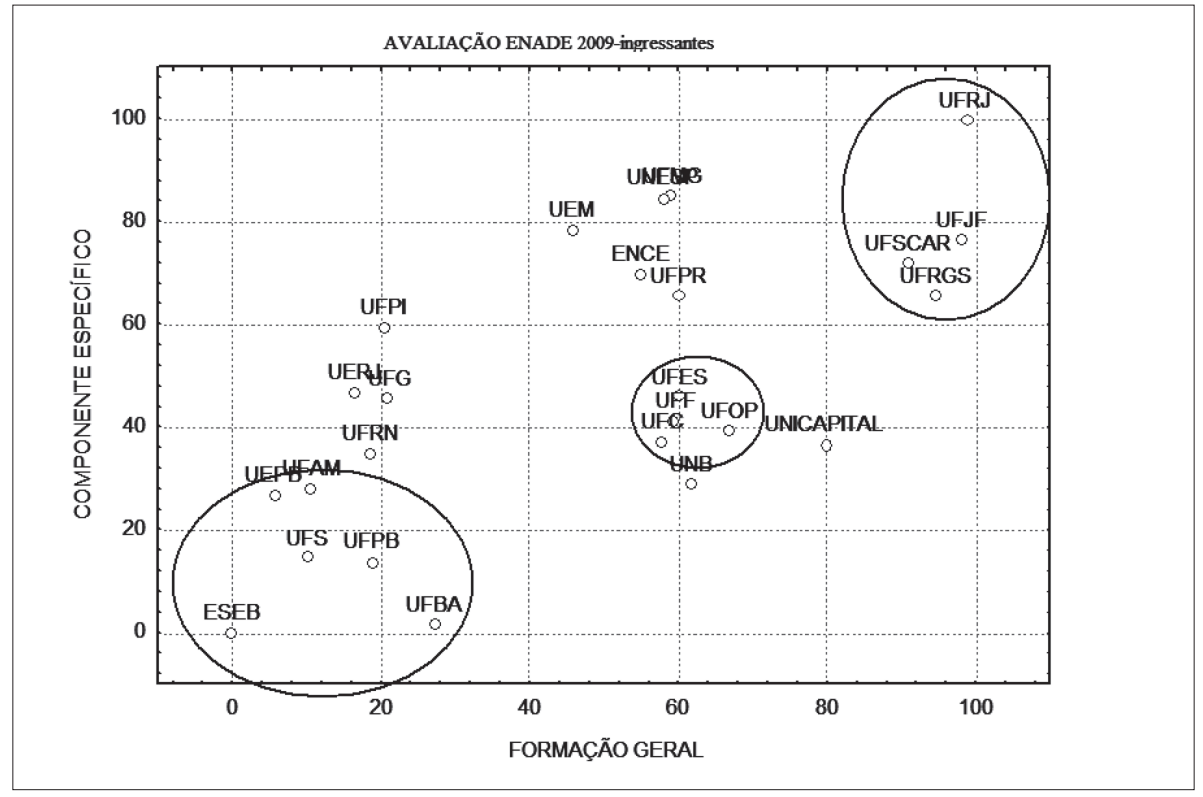

Figura 2 - Percentis da Curva Normal Padrão para IES,

ENADE/Avaliação dos concluintes

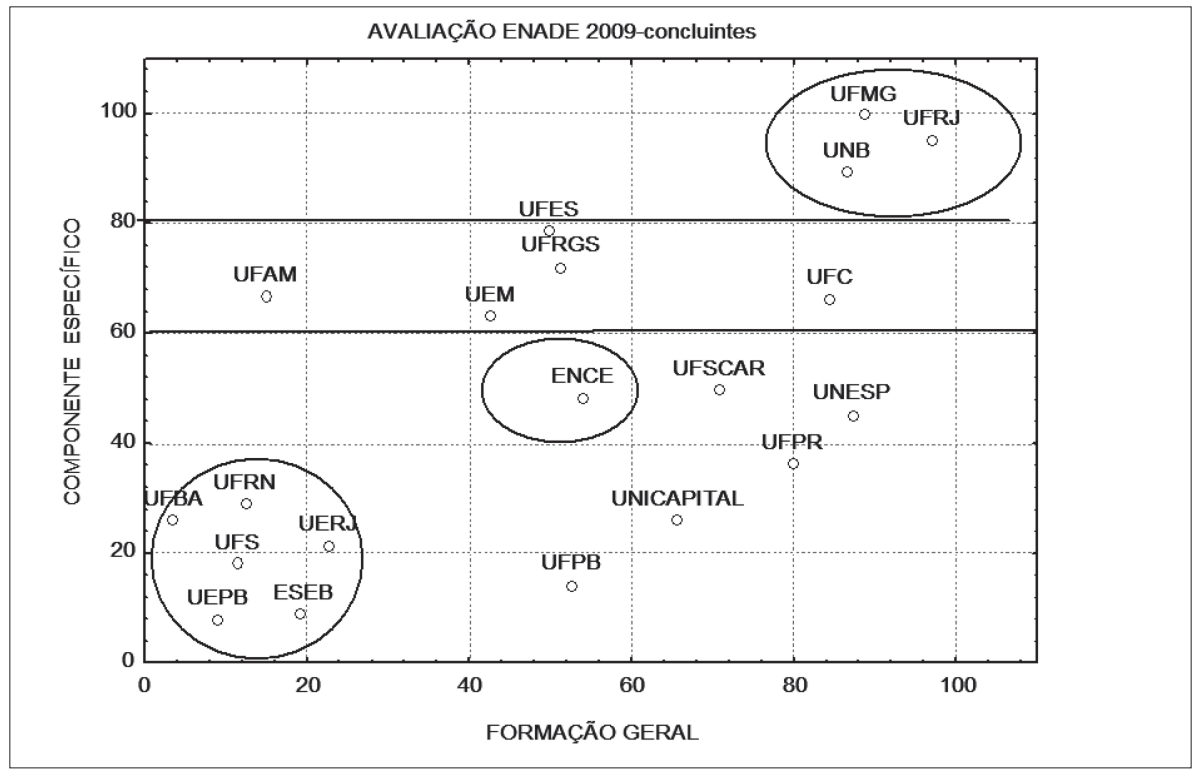


A análise em nível regional, Tabela 3, mostra as médias das avaliações dos alunos concluintes tanto para a Formação Geral quanto para Específica tem variabilidade relativa abaixo $30 \%$ em todas as regiões, o que traduz a homogeneidade da aprendizagem, isto é, a média representa fielmente a aquisição do conteúdo programático proposto. No caso dos alunos ingressantes, a variabilidade foi ainda menor, infere que a potencialidade para apreensão de novos conhecimentos gera igualdade. A média dos concluintes ao se aproximar dos ingressantes caracteriza um cenário de aprendizagem preocupante, uma vez que se esperava um patamar mais elevado para os concluintes.

Tabela 3 - Desempenho discente a nível regional

\begin{tabular}{|c|c|c|c|c|c|c|}
\hline \multirow[b]{2}{*}{$\begin{array}{c}\text { Medidas } \\
\text { Estatísticas }\end{array}$} & \multicolumn{3}{|c|}{ Notas Concluintes } & \multicolumn{3}{|c|}{ Notas Ingressantes } \\
\hline & $\begin{array}{c}\text { Formação } \\
\text { Geral }\end{array}$ & $\begin{array}{c}\text { Componente } \\
\text { Específico }\end{array}$ & $\begin{array}{l}\text { ENADE } \\
\text { contínuo }\end{array}$ & $\begin{array}{c}\text { Formação } \\
\text { Geral }\end{array}$ & $\begin{array}{c}\text { Componente } \\
\text { Específico }\end{array}$ & $\begin{array}{l}\text { ENADE } \\
\text { Contínuo }\end{array}$ \\
\hline \multicolumn{7}{|c|}{ Norte } \\
\hline Média & 37,76 & 27,77 & 1,49 & 31,41 & 16,44 & 1,2 \\
\hline CV (\%) & 15,89 & 25,07 & 35,14 & 6,81 & 7,56 & 11,55 \\
\hline \multicolumn{7}{|c|}{ Nordeste } \\
\hline Média & $33,36(1)$ & $23,82(1)$ & 0,95 (1) & $34,15(2)$ & $17,01(2)$ & $1,37(2)$ \\
\hline CV $(\%)$ & 29,33 & 23,95 & 87,71 & 19,11 & 21,58 & 45,62 \\
\hline \multicolumn{7}{|c|}{ Sudeste } \\
\hline Média & 48,36 & 38,46 & 2,9 & 50,65 & 23,11 & 2,81 \\
\hline CV (\%) & $21,15(3)$ & $28,61(3)$ & $48,29(3)$ & 23 & 19,36 & 34,63 \\
\hline \multicolumn{7}{|c|}{ Sul } \\
\hline Média & 48,06 & 30,42 & 2,08 & 51,94 & 22,84 & 2,8 \\
\hline CV (\%) & 10,14 & 12,5 & 15,58 & 14,05 & 9,1 & 11,28 \\
\hline \multicolumn{7}{|c|}{ Centro-Oeste } \\
\hline Média & $\ldots$ & $\ldots$ & $\ldots$ & 40,95 & 18,9 & 1,86 \\
\hline CV (\%) & $\ldots$ & $\ldots$ & $\ldots$ & 15,79 & 5,8 & 0,32 \\
\hline
\end{tabular}

Nota: (1) Exclusive UFPI; (2) Exclusive ESEB; (3) Exclusive UFJF, UFOP e UFF;(4) Resguardado sigilo

$\mathrm{Na}$ Tabela 4, o número médio de participantes ingressantes superou o de concluintes, talvez a explicação deva-se ao fato de que há um contingente reduzido de alunos que completam o curso de Estatística. Outra razão possível, 
é que as vagas destinadas ao vestibular ainda são escassas, dado que a relação candidato/vaga não se apresenta economicamente viável.

Tabela 4 - Estatísticas da participação

\begin{tabular}{|c|c|c|c|}
\hline \multirow{2}{*}{ Medidas Estatísticas } & \multicolumn{3}{|c|}{ Número Médio de Participantes } \\
\hline & Ingressantes & Concluintes & Total \\
\hline \multicolumn{4}{|c|}{ Norte } \\
\hline Média & 28 & 20,5 & 48,5 \\
\hline CV (\%) & 7,14 & 31,71 & 9,28 \\
\hline \multicolumn{4}{|c|}{ Nordeste } \\
\hline Média & 29,57 & 16,29 & 45,86 \\
\hline CV $(\%)$ & 56,81 & 83,92 & 48,49 \\
\hline \multicolumn{4}{|c|}{ Sudeste } \\
\hline Média & 23,5 & 14,38 & 37,88 \\
\hline CV $(\%)$ & 66,81 & 117,64 & 75,76 \\
\hline \multicolumn{4}{|c|}{ Sul } \\
\hline Média & 31,5 & 24 & 55,5 \\
\hline CV $(\%)$ & 71,12 & 51,59 & 61,29 \\
\hline \multicolumn{4}{|c|}{ Centro-Oeste } \\
\hline Média & 35 & 14,5 & 49,5 \\
\hline CV (\%) & 2,86 & 100 & 31,31 \\
\hline
\end{tabular}

Nota: (1) Exclusive UFPI; (2) Exclusive ESEB; (3) Exclusive UFJF, UFOP e UFF;(4) Resguardado sigilo

Os Conselhos Regionais de Estatística estão se empenhando na divulgação das áreas de atuação do estatístico junto à sociedade, no setor público e privado. No processo empregatício as exigências do fazer do estatístico na visão dos gestores têm estado muito além da capacitação oferecida aos concluintes. Assim, a educação continuada torna-se mais um pré-requisito no mundo do trabalho. Esta reflexão está relacionada aos resultados do ENADE, quando apresentou nota contínua do ENADE abaixo do valor mediano $(2,5)$, embora haja variabilidade alta $(45,62 \%)$ na região Sudeste.

A declaração do tipo de regime dos docentes mostrou que apenas três IES utilizam regime parcial, Tabela 5, UFAM, UNICAPITAL e UERJ, mas cabe esclarecer que os estudantes da UNICAPITAL não estiveram presentes para a realização da prova. 
Tabela 5 - Índice de avaliação de equipamentos, plano de ensino e titulação de docentes

\begin{tabular}{|c|c|c|c|c|c|c|}
\hline \multirow{2}{*}{ IES } & \multicolumn{2}{|c|}{ Proporção de discentes } & \multicolumn{2}{|c|}{$\begin{array}{l}\text { Proporção de } \\
\text { titulação mínima }\end{array}$} & \multirow{2}{*}{$\begin{array}{c}\text { Regime } \\
\text { Parcial/Integral }\end{array}$} & \multirow{2}{*}{$\begin{array}{c}\text { ENADE } \\
\text { CPC } \\
\text { Faixa }\end{array}$} \\
\hline & $\begin{array}{l}\text { Suficiência de } \\
\text { equipamentos }\end{array}$ & $\begin{array}{l}\text { Bom plano } \\
\text { de ensino }\end{array}$ & Mestres & Doutores & & \\
\hline \multicolumn{7}{|c|}{ Norte } \\
\hline UFAM & 0,3514 & 0,3784 & 0,7000 & 0,4500 & 0,7000 & 2 \\
\hline UFPA & 0,2162 & 0,1622 & 0,8485 & 0,5455 & 1,0000 & 2 \\
\hline \multicolumn{7}{|c|}{ Nordeste } \\
\hline UFRN & 0,6471 & 0,5000 & 0,7215 & 0,5063 & \multirow{4}{*}{1,0000} & 3 \\
\hline UFBA & 0,4545 & 0,4091 & 0,6279 & 0,4186 & & 2 \\
\hline UFSE & 0,1111 & 0,5556 & 0,7083 & 0,1250 & & 2 \\
\hline UFC & 0,6275 & 0,3654 & 0,8049 & 0,4634 & & 3 \\
\hline ESEB & 0,0476 & 0,0476 & - & - & - & SC \\
\hline UEPB & 0,3425 & 0,2676 & 0,7000 & 0,3000 & \multirow{2}{*}{1,0000} & 2 \\
\hline UFPI & 0,4444 & 0,4444 & 0,5000 & 0,1667 & & $\mathrm{SC}$ \\
\hline \multicolumn{7}{|c|}{ Sudeste } \\
\hline UFMG & 0,7632 & 0,5128 & 0,9787 & 0,8936 & \multirow{5}{*}{1,0000} & 5 \\
\hline UFJF & 0,5714 & 0,0000 & 0,7500 & 0,6250 & & $\mathrm{SC}$ \\
\hline UFOP & 0,8824 & 0,3750 & 0,8364 & 0,4182 & & $\mathrm{SC}$ \\
\hline UFRJ & 0,6667 & 0,3636 & 0,9730 & 0,7838 & & 5 \\
\hline ENCE & 0,9077 & 0,5077 & 0,9444 & 0,4444 & & 3 \\
\hline UERJ & 0,4500 & 0,1975 & 0,7937 & 0,6032 & 0,9524 & 2 \\
\hline UFF & 0,8095 & 0,3500 & 0,9487 & 0,7436 & \multirow[t]{2}{*}{1,0000} & SC \\
\hline UFES & 0,6957 & 0,3478 & 0,8519 & 0,6296 & & 4 \\
\hline \multicolumn{7}{|c|}{ Sul } \\
\hline UFSCAR & 0,7170 & 0,2642 & 0,9367 & 0,7089 & 1,0000 & 4 \\
\hline UNICAPITAL & 0,8261 & 0,1304 & 0,6154 & 0,0769 & 0,2308 & 2 \\
\hline UNESP & 0,7333 & 0,5000 & 1,0000 & 0,7000 & \multirow{4}{*}{1,0000} & 4 \\
\hline UFPR & 0,5714 & 0,2887 & 1,0000 & 0,6429 & & 3 \\
\hline UEM & 0,7778 & 0,5185 & 0,9048 & 0,7143 & & 4 \\
\hline UFRGS & 0,7429 & 0,5714 & 0,8318 & 0,5234 & & 4 \\
\hline \multicolumn{7}{|c|}{ Centro-oeste } \\
\hline UFG & 0,8214 & 0,7143 & 1,0000 & 0,2857 & \multirow{2}{*}{1,0000} & SC \\
\hline UNB & 0,5636 & 0,5185 & 0,8989 & 0,6915 & & 4 \\
\hline
\end{tabular}

Os alunos opinaram sobre infra-estrutura, processo pedagógico adotado pela IES e composição do grupo docente quanto à titulação mínima pode ser visualizada também na Tabela 6 . A suficiência de equipamentos está presente nas IES das regiões Sudeste, Sul e Centro-Oeste, sendo que as duas primeiras são as que possuem maior percentual de doutores (titulação mínima), regiões em que os professores estão aptos para concorrer aos editais de órgãos de fomento para obter repasse de recursos para suprir infra-estrutura. 
Tabela 6 - Conceito Preliminar dos Cursos segundo critérios de avaliação

\begin{tabular}{|c|c|c|c|c|c|}
\hline \multirow{3}{*}{ Siglas } & \multirow{3}{*}{$\begin{array}{l}\text { Conceito } \\
\text { Contínuo } \\
\text { Preliminar }\end{array}$} & \multicolumn{4}{|l|}{ Notas } \\
\hline & & \multirow{2}{*}{ Infra-estrutura } & \multirow{2}{*}{$\begin{array}{l}\text { Organização } \\
\text { Didático- } \\
\text { Pedagógica }\end{array}$} & \multicolumn{2}{|c|}{ Docentes } \\
\hline & & & & Mestres & Doutores \\
\hline UFMG & 4,49 & 4,16 & 3,59 & 4,79 & 5 \\
\hline UFRJ & 4,28 & 3,60 & 2,55 & 4,73 & 4,33 \\
\hline Média & 4,39 & 3,88 & 3,07 & 4,76 & 4,67 \\
\hline Desvio Padrão & 0,11 & 0,28 & 0,52 & 0,03 & 0,33 \\
\hline CV & $2,45 \%$ & $7,78 \%$ & $20,39 \%$ & $0,63 \%$ & $7,74 \%$ \\
\hline UNB & 3,39 & 3,00 & 3,63 & 3,99 & 3,76 \\
\hline UFES & 2,96 & 3,77 & 2,43 & 3,52 & 3,38 \\
\hline UFRGS & 2,95 & 4,04 & 4,00 & 3,32 & 2,73 \\
\hline UNESP & 3,1 & 3,99 & 3,50 & 5 & 3,81 \\
\hline UEM & 3,04 & 4,24 & 3,63 & 4,05 & 3,9 \\
\hline UFSCAR & 2,95 & 3,89 & 1,85 & 4,37 & 3,87 \\
\hline Média & 3,07 & 3,82 & 3,17 & 4,04 & 3,58 \\
\hline Desvio Padrão & 0,16 & 0,39 & 0,76 & 0,55 & 0,42 \\
\hline CV & $5,27 \%$ & $10,14 \%$ & $41,35 \%$ & $12,61 \%$ & $10,73 \%$ \\
\hline UFC & 2,69 & 3,37 & 2,56 & 3,05 & 2,37 \\
\hline ENCE & 2,62 & 5,00 & 3,55 & 4,44 & 2,25 \\
\hline UFPR & 2,69 & 3,05 & 2,02 & 5,00 & 3,46 \\
\hline UFRN & 1,95 & 3,48 & 3,5 & 2,22 & 2,63 \\
\hline Média & 2,49 & 3,73 & 2,91 & 3,68 & 2,68 \\
\hline Desvio Padrão & 0,31 & 0,75 & 0,65 & 1,10 & 0,47 \\
\hline CV & $15,98 \%$ & $21,63 \%$ & $18,47 \%$ & $49,59 \%$ & $17,95 \%$ \\
\hline UFAM & 1,88 & 1,77 & 2,65 & 2,00 & 2,28 \\
\hline UFPA & 1,7 & 0,98 & 1,14 & 3,48 & 2,87 \\
\hline UERJ & 1,89 & 2,34 & 1,38 & 2,94 & 3,22 \\
\hline UFS & 1,08 & 0,37 & 3,89 & 2,08 & 0,29 \\
\hline UEPB & 1,05 & 1,71 & 1,87 & 2,00 & 1,37 \\
\hline UNICAPITAL & 1,33 & 4,53 & 0,91 & 1,15 & 0,00 \\
\hline Média & 1,49 & 1,95 & 1,97 & 2,28 & 1,67 \\
\hline Desvio Padrão & 0,35 & 1,31 & 1,03 & 0,75 & 1,22 \\
\hline CV & $34 \%$ & $76,75 \%$ & $54,88 \%$ & $37,36 \%$ & $89,39 \%$ \\
\hline UFJF & & 3,05 & 0,00 & 2,5 & 3,36 \\
\hline UFOP & & 4,85 & 2,63 & 3,36 & 2,09 \\
\hline UFPI & & 2,31 & 3,11 & 0 & 0,55 \\
\hline UFF & & 4,43 & 2,45 & 4,49 & 4,08 \\
\hline UFG & & 4,50 & 5,00 & 5,00 & 1,28 \\
\hline ESEB & & 0,00 & 0,33 & 0,00 & 0,00 \\
\hline Média & & 3,19 & 2,25 & 2,56 & 1,89 \\
\hline Desvio Padrão & & 1,68 & 1,69 & 1,98 & 1,46 \\
\hline CV & & $37,38 \%$ & $33,90 \%$ & $39,52 \%$ & $113,83 \%$ \\
\hline
\end{tabular}

Nota: CV: Coeficiente de Variação 
No que se refere à avaliação quanto a um bom plano de ensino, a UFG foi à melhor julgada pelos alunos, Tabela 6, embora não tenha conceito definido, pois ainda não há concluintes. Assim, acredita-se ter havido certa mobilização para realização desta avaliação. Este mesmo aspecto foi avaliado por 51,28\% - UFMG e 36,36\% - UFRJ dos alunos da região Sudeste, IES que obtiveram conceito cinco. Estes achados mostram o descompasso de mobilização, considerando que na segunda região, tanto ingressantes quanto concluintes tinham garantida a oportunidade de participação. Se o aluno não participa do ENADE e por conseqüência se omite de julgar o plano de ensino, cabe aos coordenadores de curso procurar levantar as possíveis causas da não adesão ao processo avaliativo das IES. Talvez os alunos desconheçam o que está proposto nas Diretrizes Curriculares do Curso de Estatística por falta de divulgação ou desinteresse; ou, ainda, o plano de ensino pode estar se distanciando das expectativas dos alunos em relação às habilidades e competências exigidas pelo mercado de trabalho.

Nesta mesma tabela, Tabela 6 mostra que apenas duas das vinte IES (UFMG e da UFRJ) mereceram conceito máximo com variação nos resultados das avaliações de $2 \%$ e apenas uma dentre as demais obtiveram conceito 4 (quatro). Esta aferição traduz-se em alerta, uma vez que o mercado de trabalho encontra-se em plena expansão para o profissional estatístico que lida com algoritmos da área probabilística, principalmente na gestão de qualidade dos serviços públicos e privados.

A medida relativa à infra-estrutura, questionada pela pergunta "Aulas práticas: os equipamentos disponíveis são suficientes para todos os alunos?", mostrou que as IES públicas localizadas no Norte e Nordeste do país (exceto a UERJ, no sudeste) são as que obtiveram menores notas, apesar da existência de Programas de Incentivo a Capacitação Docente. Cabe ainda ressaltar que a nota de avaliação de titulação encontra-se abaixo da mediana, cenário que apresenta cursos com conceito contínuo igual ou inferior a dois e também são os que apresentam notas mais baixas em titulação.

A avaliação do segmento relativo à Organização Didático-Pedagógica com a questão, "Os planos de ensino contêm todos os seguintes aspectos: objetivos; procedimentos de ensino e avaliação; conteúdos e bibliografia da disciplina?" foram bem pontuados para as instituições UFRGS, UFS, UNB e UEM, embora a EFS tenha tido baixa pontuação em infra-estrutura e em relação à titulação.

As notas atribuídas à avaliação da infraestrutura, organização didático pedagógica, corpo docente e regime de trabalho adotado pela IES no cenário das 
macro-regiões do Brasil, mostram que a Região Norte é aquela que está mais bem estruturada no quesito infraestrutura. $\mathrm{O}$ aspecto da organização didático pedagógica foi o item que apresentou mais dispersão nos valores médios, o que mostra uma heterogeneidade na forma de conduzir a transmissão dos conhecimentos, apesar da existência das Diretrizes Curriculares. Na avaliação do corpo docente (grau máximo cinco) as médias regionais estão um pouco acima do valor mediano, a exceção da Região Nordeste.

A distribuição das IES segundo as cidades de origem, Figura 3, mostra que Belo Horizonte, Rio de Janeiro e Brasília são as que estão mais preparadas para atender as solicitações dos gestores dos setores privado e público, seguida de Fortaleza, estas lideram em qualidade no ensino tanto Formação Geral quanto na Específica, sendo que na Específica há exigência que o aluno domine conteúdos de Estatística Inferencial bem como algoritmos no espaço multivariado. As IES das demais cidades devem repensar a formação de seus alunos, pois se encontram fora do quadrante superior direito (qualidade superior).

Figura 3 - Cenário das cidades segundo avaliação do ENADE - Estatística dos concluintes

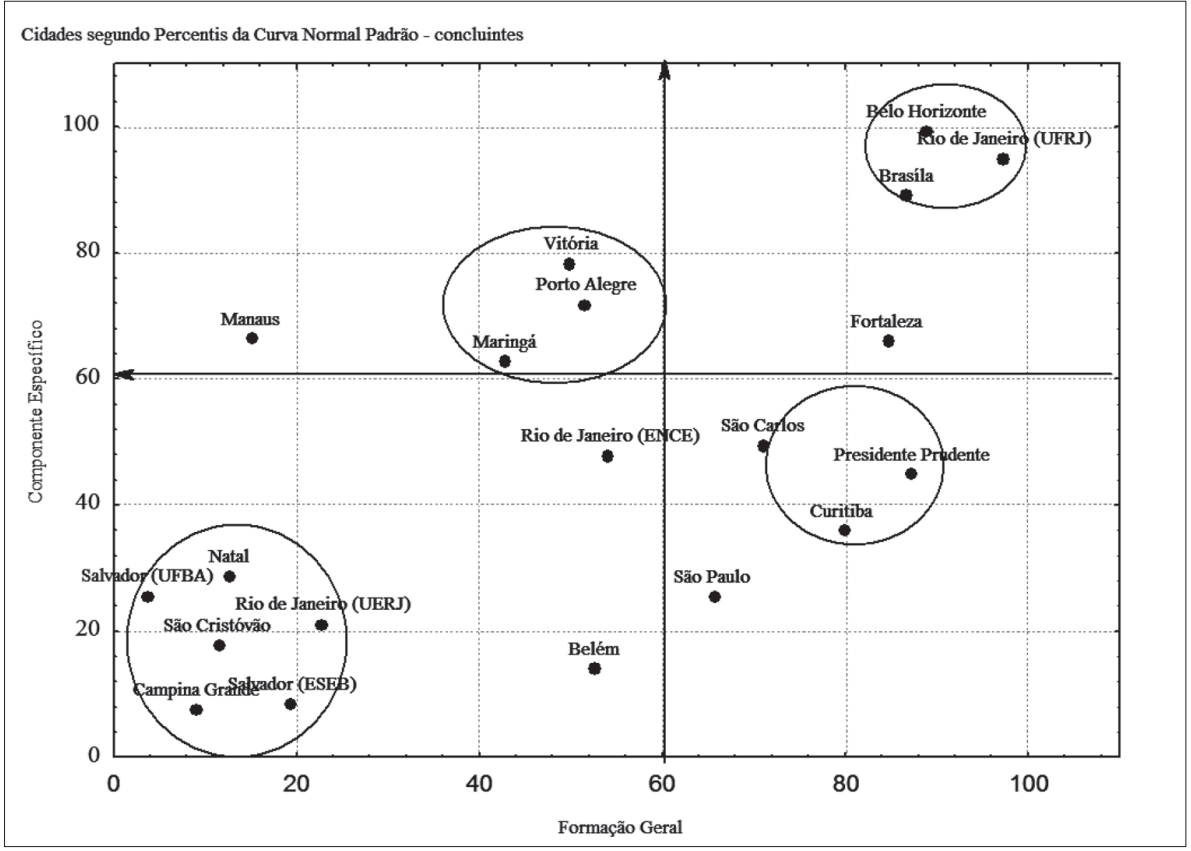


Nesta situação o problema que emerge, é que o estatístico necessita de conteúdos de Formação Geral, tendo em vista que trabalha junto a equipes multidisciplinares. No grupo das cidades São Carlos, Presidente Prudente e Curitiba a relação se inverte, este concluinte, possivelmente não tem robustez suficiente no emprego adequado das ferramentas da Estatística. Maior atenção dos gestores do ensino deve ser dada as cidades cujos cursos se encontram no quadrante inferior esquerdo, uma vez que claudicam tanto na Formação Geral quanto na Específica.

Todas as medidas originais relativas às provas de formação geral e componente específico foram padronizadas e transformadas em notas entre 0 e 5 . A medida original de cada curso é subtraída da média obtida para a área do curso e o resultado é dividido pelo desvio padrão e para que todas as instituições tenham notas variando de 0 a 5 é feito o seguinte ajuste: soma-se ao afastamento padronizado de cada curso, o módulo do menor afastamento padronizado entre os cursos da área e divide-se pela soma do maior afastamento padronizado com o módulo do menor. Então, multiplica-se o resultado desse quociente por 5 e este resultado corresponde a Nota Padronizada do curso. Os cursos que obtiverem Afastamento Padronizado menor que -3,0 e maior que 3,0 não foram utilizados como ponto inferior ou superior e recebem Nota Padronizada igual a 0 (zero) e 5 (cinco), respectivamente, valores de desempenho muito discrepantes dos demais da sua área (outliers). A ordenação da IES quanto ao Conceito Preliminar de Curso (CPC) estão na Tabela 7, na próxima página.

Os resultados mostraram que curso de Estatística da URFJ apresentou o melhor desempenho em função valor médio dos conceitos obtidos tanto para ingressantes quanto para concluintes. O curso da UFJF, da FSCAR e da UFRGS são os ingressantes, no entanto, em relação aos concluintes, UFMG e UNB que se aproximaram da UFRJ.

\section{CONCLUSÃO E RECOMENDAÇÕES}

Esta avaliação será reaplicada em 2013, sendo observado se houve empenho de melhora nas medidas que compõe o Conceito Preliminar de Curso e nesta segunda avaliação, o ENADE computará o Indicador da Diferença entre os Desempenhos Esperado e Observado (IDD).

Os Conselhos Regionais de Estatística - CONRE deverão estar atentos aos próximos resultados avaliativos dos cursos de Estatística no tocante a qualidade na formação de graduados, pois cabe a estes órgãos a responsabilidade do registro profissional segundo a Regulamentação da Profissão de Estatístico 
Tabela 7 - Ordenação das IES segundo os conceitos do ENADE/2009- Estatística

\begin{tabular}{|c|c|c|c|}
\hline \multirow{2}{*}{ Sigla } & \multirow{2}{*}{ Unidade da Federação } & \multicolumn{2}{|c|}{ Conceito } \\
\hline & & Contínuo & Faixa do ENADE \\
\hline UFMG & MG & 4,77 & \multirow{2}{*}{5} \\
\hline UFRJ & RJ & 4,16 & \\
\hline UNB & DF & 3,50 & 4 \\
\hline UFES & ES & \multirow{8}{*}{2,70 a 1,95} & \multirow{8}{*}{3} \\
\hline UFC & CE & & \\
\hline UFRGS & RS & & \\
\hline UNESP & SP & & \\
\hline UEM & PR & & \\
\hline UFSCAR & SP & & \\
\hline UFAM & AM & & \\
\hline ENCE & RJ & & \\
\hline UFPR & PR & \multirow{5}{*}{1,90 a 0,95} & \multirow{5}{*}{2} \\
\hline UNICAPITAL & SP & & \\
\hline UFRN & RN & & \\
\hline UFPA & PA & & \\
\hline UERJ & RJ & & \\
\hline UFBA & BA & \multirow{4}{*}{0,73 a 0,15} & \multirow{4}{*}{1} \\
\hline UFS & SE & & \\
\hline UEPB & PB & & \\
\hline ESEB & BA & & \\
\hline
\end{tabular}

pela Lei no. 4.739, de 15 de julho de 1965. Recomenda-se que as IES não negligenciem suas atribuições de formação profissional.

O site http://www.careercast.com/jobs/content/JobsRated_Top200Jobs divulgou uma pesquisa americana que ordena as melhores e piores profissões e dentre as quatro melhores profissões estão: Matemática, Atuária, Estatística e Biologia. Os Estatísticos estão tendo mais prestígio, pois os métodos inferenciais das Ciências Estatísticas têm sido cada vez mais utilizados. A continuidade deste prestígio está atrelada à boa formação acadêmica e profissional de nossos universitários. "Cabe aos professores o compromisso de transmitir o saber Estatístico, considerando como fonte prioritária, as Diretrizes Curriculares para Cursos de Estatística".

O reconhecimento da Estatística como uma das melhores profissões propicia a demanda para a construção de parcerias, o que vem enriquecer os grupos profissionais multidisciplinares, onde o trabalho de qualidade seja observado para que se evitem constrangimentos quanto ao uso indevido das metodologias estatísticas. 
Há três grandes perfis referenciais para os formandos em Estatística: Estatístico-Pesquisador: que se ocupará das atividades de pesquisa em estatística em universidades e centros de pesquisa. Estatístico-Educador: dedicar-se-á à disseminação do conhecimento estatístico em diferentes organizações sociais, mas de forma especial nas escolas de ensino médio. Estatístico Aplicado: profissional capacitado a formular e resolver problemas que envolvem a coleta, e sistematização e análise de dados.

\section{REFERÊNCIAS}

BRASIL.MINISTÉRIO DA EDUCAÇÃO. Lei nº 10.861, de 14/04/2004. 2004a. Institui o Sistema Nacional de Avaliação da Educação Superior SINAES e dá outras providências. Disponível em: www.planalto.gov.br/ ccivil_03/_ato2004-2006/.../lei/110.861.htm>. Acesso em: 1 ago. 2011.

BRASIL.MINISTÉRIO DA EDUCAÇÃO. Portaria n 2.051/04 MEC de 09/07/2004. 2004b. Regulamenta os procedimentos de avaliação do Sistema Nacional de Avaliação da Educação Superior (SINAES), instituído na Lei no 10.86 1, de 14 de abril de 2004. Disponível em: <www2.mec.gov.br/sapiens/ portarias/port4362.pdf>. Acesso em: 01 ago. 2011.

BRASIL.MINISTÉRIO DA EDUCAÇÃO, CONSELHO NACIONAL DE EDUCAÇÃO, CÂMARA DE EDUCAÇÃO SUPERIOR. Resolução no 8, de 28 de novembro de 2008. 2008. Institui as Diretrizes Curriculares Nacionais do curso de Estatística, de graduação plena, em nível superior, e dá outras providências. Disponível em: http://portal.mec.gov.br/cne/arquivos/ pdf/2008/rces008_08.pdf $>$. Acesso em: 01 ago. 2011.

BRASIL.MINISTÉRIO DA EDUCAÇÃO GABINETE DO MINISTRO. Portaria Normativa $\mathbf{n}^{\mathbf{0}} \mathbf{1}$, de 29 de janeiro de 2009. 2009. Determina as áreas e os cursos superiores de tecnologia que serão avaliados pelo Exame Nacional de Desempenho dos Estudantes (ENADE) no ano de 2009 e dá outras providências. Disponível em: http://www.anaceu.org.br/conteudo/ legislacao/portarias/2009. Acesso em: 1 ago. 2011

BUSSAB, Wilton de Oliveira; MORETTIN, Pedro Alberto. Estatística básica. São Paulo: Saraiva, 2002.

CONSELHO REGIONAL DE ESTATÍSTICA, CONRE2(RJ,ES).

Regulamentação da profissão de estatístico. Disponível em: $<$ http://www. conre2.org.br/resolucao8.pdf>. Acesso em: 6 ago. 2011. 
